Journal of Ocean Engineering and Technology 26(6), 46-52, December, 2012 http://dx.doi.org/10.5574/KSOE.2012.26.6.046

\author{
선수파 중 슬로싱을 고려한 병렬배치된 두 부유체의 \\ 거동 특성에 관한 실험 연구 \\ 조석규·성홍근 · 홍장표·홍사영 · 홍석원 \\ 한국해양과학기술원 선박해양플랜트연구소
}

\title{
Experimental Study of Motion Behavior of Side-by-Side Moored Two Floating Bodies Including Sloshing in Head Sea
}

\author{
Seok-Kyu Cho, Hong-Gun Sung, Jang-Pyo Hong, Sa-Young Hong and Seok-Won Hong \\ Maritime and Ocean Engineering Research Institute, KIOST, Daejeon, Korea
}

KEY WORDS: Sloshing 슬로싱, Side-by-Side 병렬배치, Floating Body 부유체, Experiment 모형시험, Gap Flow 틈새유동

ABSTRACT: The motions and drift forces of side-by-side moored FSRU and LNGC including the sloshing effect, were studied using experiments. The FSRU and LNGC contained LNG cargo tanks and the LNG sloshing could affect the motions and drift forces of the structures due to its coupling with floating body motion. The effect of coupling can vary with the LNG filling level, and the effect of the filling level was investigated. The coupling effect was stronger at lower filling level. It was confirmed that longitudinal sloshing influenced the surge and surge mean drift force in head sea. In addition, gap flow affected the sway and mean drift forces. Sloshing attenuated the sway and yaw excited by gap flow in side-by-side configuration.

\section{1. 서 론}

최근 $\mathrm{LNG}($ Liquefied natural gas)의 수요가 증가하면서 LNG 선박의 대형화가 이루어지고 있으며 FSRU(Floating storage \& regasification unit), $\mathrm{RV}$ (Regasification vessel)와 같이 대형 화 물창을 갖는 새로운 개념의 선박이 등장하고 있다. 부유식 LNG 구조물과 LNG 운반선 사이에서 수행되는 LNG 이송은 병렬배치 (Side-by-side) 또는 직렬배치(Tandem) 상태에서 이루어진다. 해 상에서 $\mathrm{LNG}$ 를 이송하기 위해서는 $-162^{\circ} \mathrm{C}$ 의 저온 $\mathrm{LNG}$ 와 상온의 외기 온도차를 차단할 수 있는 절연 이송관이 필요하다. 저온의 절 연된 이송관의 취성 파괴를 피하기 위해서 이송관의 길이는 가능한 짧아야하고, 따라서 병렬배치 또는 근접 직렬배치 상태에서 이송 을 해야 한다. 근접 직렬배치에 대한 연구도 진행되고 있지만 (Clauss et al. 2010), 병렬배치 상태에서 LNG 하역 및 이송 연구가 보다 많이 수행되고 있다. 두 부유체가 병렬배치되어 있을 때 유체역학 적으로 중요한 문제는 부유체 사이에서 발생하는 틈새유동(Gap flow)과 선체운동에 기인한 화물창 내 LNG의 슬로싱이다.

병렬배치된 두 부유체의 운동응답에 대한 연구는 오랫동안 꾸준히 수행되어 왔다. 부유체와 슬로싱 연성에 관한 문제도 선 박유체역학 분야의 오래된 연구주제이다. 몇 가지 예를 들면 Hong et al.(2005), Hong et al.(2009), Jeong et al.(2010), Hansen et al. (2009)은 병렬배치된 부유체에 대하여 모형실험과 수치해석을 통 해 부유체 운동, 틈새유동, 표류력, 계류시스템의 응답을 규명하 였다. 한편, 부유체 운동과 슬로싱 연성에 관한 대표적인 연구 로는 Kim et al.(2007)의 비선형 횡동요 응답 연구, Rognebakke and Faltinsen(2003)의 멀티 모달 및 모형실험 연구, Clauss et al.(2010)의 LNGC(Liquefied natural gas carrier)의 슬 로싱 연성 모형실험, Gaillarde et al.(2004)의 모형실험 연구를 들 수 있다. 한편 슬로싱을 포함한 병렬배치된 부유체에 대한 연구는 아직 충분하지 않다. 현재까지 발표된 연구로 Lee et al.(2007, 2008)와 Cho et al.(2011, 2012), Cho(2012)의 논문을 들 수 있다. Lee et al.(2008)은 횡파 중 병렬배치된 FPSO(Floating production storage and offloading)와 LNGC의 응답을 LNGC에 발생 하는 슬로싱을 포함하여 해석하였다. 한편 Cho(2012), Cho et al. (2011, 2012)은 병렬배치된 FSRU(Floating storage and regasification unit)와 LNGC의 선형운동응답과 표류력을 슬로싱을 포함 한 모형실험과 수치해석으로 계산하였다. 슬로싱을 포함한 상 태에서 병렬배치된 부유체의 응답은 파랑 입사각, 선수각 회전 여부, 슬로싱 조건, 부유체 틈새 간격, 병렬배치 계류 등 고려해 야하는 변수가 매우 많다. 이러한 변수를 모두 종합적으로 고려

\section{Received 8 October 2012, revised 12 November 2012, accepted 11 December 2012}

Corresponding author Seok-Kyu Cho, +82-42-866-3933, skcho33@kiost.ac

(c) 2012, The Korean Society of Ocean Engineers 
한 연구는 아직까지 수행된 바 없다. 본 논문에서는 선수파 중 슬로싱을 포함한 병렬배치된 FSRU와 LNGC의 연성 운동, 표류 력 및 틈새유동에 대한 모형실험을 수행하여 슬로싱과 틈새유 동에 의한 운동 특성을 고찰하였다.

\section{2. 모형 실험}

\section{1 대상선}

실험에 사용한 부유체는 FSRU와 LNGC이고, 주요 치수는 Table 1 과 2와 같다. FSRU에는 빌지킬이 있는데, 빌지킬의 길이는 180.5 $\mathrm{m}$, 폭은 $1.25 \mathrm{~m}$, 연직 방향에 대하여 $45 \mathrm{deg}$ 로 설치되었다. FSRU의 길이는 $315 \mathrm{~m}$, 폭은 $53 \mathrm{~m}$ 이며, $\mathrm{LNGC}$ 의 길이는 $266 \mathrm{~m}$, 폭은 $43.4 \mathrm{~m}$ 이다. 모형선의 축척비는 $1 / 60$ 이다.

Table 1 Particulars of FSRU

\begin{tabular}{ccc}
\hline \hline Loading condition & & Design \\
\hline Lpp & {$[\mathrm{m}]$} & 315.0 \\
B & {$[\mathrm{m}]$} & 53.0 \\
Draft & {$[\mathrm{m}]$} & 12.0 \\
Displacement Total & {$\left[\mathrm{m}^{3}\right]$} & 195,444 \\
Roll natural Period & {$[\mathrm{s}]$} & 18.60 \\
\hline
\end{tabular}

Table 2 Particulars of LNGC

\begin{tabular}{cccc}
\hline \hline \multicolumn{2}{c}{ Loading condition } & Full & Ballast \\
\hline Lpp & {$[\mathrm{m}]$} & 266 & 266 \\
B & {$[\mathrm{m}]$} & 43.4 & 43.4 \\
Draft & {$[\mathrm{m}]$} & 15.18 & 9.4 \\
Displacement Total & {$\left[\mathrm{m}^{3}\right]$} & 134,811 & 78591 \\
Roll natural Period & {$[\mathrm{s}]$} & 16.9 & 13.7 \\
\hline
\end{tabular}

FSRU와 LNGC는 각각 $\mathrm{LNG}$ 화물창을 가지고 있다. 화물창 모형은 각주형(Prismatic)으로 내부 유동을 관찰하기 위해 투명한 아크릴로 제작하였다. FSRU와 LNGC의 화물창 제원을 Table 3 과 4 에 정리하였다. 화물창의 개수는 2 개로 선수, 선미에 설치 하였고 그 위치는 Table 3과 4에 나와 있다.

Table 3 Particulars and location of cargo tanks on FSRU

\begin{tabular}{|c|c|c|c|}
\hline Length & & {$[\mathrm{m}]$} & 36.42 \\
\hline Breadth & & {$[\mathrm{m}]$} & 41.7 \\
\hline Height & & {$[\mathrm{m}]$} & 29.08 \\
\hline Upper chamber height & & {$[\mathrm{m}]$} & 9.58 \\
\hline Lower chamber height & & {$[\mathrm{m}]$} & 4.28 \\
\hline Upper chamber angle & & [deg] & 45 \\
\hline Lower chamber angle & & [deg] & 45 \\
\hline $\begin{array}{l}x \text { Location from midship to } \\
\text { tank front }\end{array}$ & $\begin{array}{l}\text { Fore } \\
\text { After }\end{array}$ & {$[\mathrm{m}]$} & $\begin{array}{r}122.67 \\
82.17\end{array}$ \\
\hline $\begin{array}{l}\text { z Location from base to tank } \\
\text { bottom }\end{array}$ & $\begin{array}{l}\text { Fore } \\
\text { After }\end{array}$ & {$[\mathrm{m}]$} & $\begin{array}{l}5.77 \\
5.68\end{array}$ \\
\hline
\end{tabular}

Table 4 Particulars and location of cargo tanks on LNGC

\begin{tabular}{|c|c|c|c|}
\hline \multicolumn{2}{|l|}{ Length } & {$[\mathrm{m}]$} & 44.8 \\
\hline \multicolumn{2}{|l|}{ Breadth } & {$[\mathrm{m}]$} & 31.44 \\
\hline \multicolumn{2}{|l|}{ Height } & {$[\mathrm{m}]$} & 27.84 \\
\hline \multicolumn{2}{|c|}{ Upper chamber height } & {$[\mathrm{m}]$} & 8.95 \\
\hline \multicolumn{2}{|l|}{ Lower chamber height } & {$[\mathrm{m}]$} & 4.09 \\
\hline \multicolumn{2}{|l|}{ Upper chamber angle } & [deg] & 45 \\
\hline \multicolumn{2}{|l|}{ Lower chamber angle } & [deg] & 45 \\
\hline \multirow{2}{*}{$\begin{array}{l}\text { x Location from midship } \\
\text { to tank front }\end{array}$} & Fore & \multirow{2}{*}[\mathrm{m}]{} & 60.86 \\
\hline & After & & 32.86 \\
\hline \multirow{2}{*}{$\begin{array}{l}\mathrm{z} \text { Location from base to } \\
\text { tank bottom }\end{array}$} & Fore & \multirow{2}{*}[\mathrm{m}]{} & 7.14 \\
\hline & After & & 7.08 \\
\hline
\end{tabular}

\section{2 실험 방법}

병렬배치된 두 부유체의 운동과 틈새유동, 슬로싱의 연성에 대한 연구를 위해 두 부유체를 선형 스프링으로 각각 계류하여 고정하였다. 두 부유체는 각각 계류되어 독립적으로 움직인다. 이 때 LNGC는 FSRU의 우현에 위치하고, 두 부유체 사이의 간 격은 $4.5 \mathrm{~m}$ 이다(Fig. 1). 스프링의 강성은 $123 \mathrm{~N} / \mathrm{m}$ 로 동일하다. 스프링은 부유체의 파랑 운동을 구속하지 않고, 파표류력에 의 해 부유체가 표류하는 것을 방지한다. 스프링의 강성은 부유체 의 전후, 좌우동요 고유주기가 가장 긴 주기의 규칙파에 대하여 5배 이상 되도록 설정하였다(Pinkster, 1980). 선수파(180deg) 중 에서 두 부유체의 운동, 각 부유체의 표류력 그리고 틈새유동을 계측하였다.

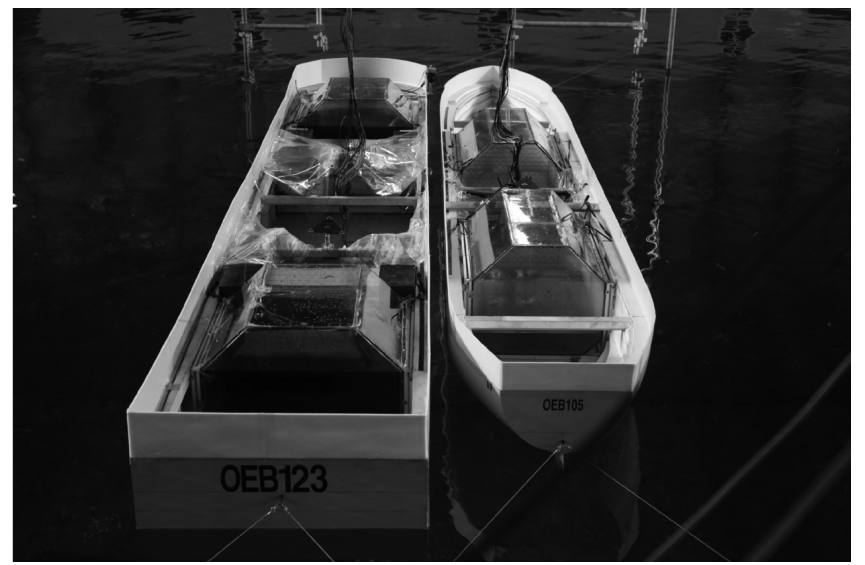

Fig. 1 Side-by-Side located FSRU and LNGC including sloshing

Table 5 LNG filling ratio conditions

\begin{tabular}{|c|c|c|c|c|}
\hline Condition & $\begin{array}{l}\text { Filling ratio of } \\
\text { FSRU [\% of cargo } \\
\text { tank height] }\end{array}$ & $\begin{array}{l}\text { Draft } \\
{[\mathrm{m}]}\end{array}$ & $\begin{array}{l}\text { Filling ratio of } \\
\text { LNGC [\% of cargo } \\
\text { tank height }]\end{array}$ & $\begin{array}{c}\text { Draft } \\
{[\mathrm{m}]}\end{array}$ \\
\hline RS(Solid) & 0 & 12.0 & 0 & 9.4 \\
\hline $\begin{array}{c}\mathrm{R} 1 \\
\text { (Berthing) }\end{array}$ & 30 & 12.0 & 95 & 15.2 \\
\hline $\begin{array}{c}\mathrm{R} 2 \\
\text { (Transfer) }\end{array}$ & 67.5 & 12.0 & 20 & 9.4 \\
\hline
\end{tabular}




\section{3 실험 조건}

실험 조건은 3 가지로 액체 화물이 없는 조건(RS), 접안 조건 (R1), LNG 이송 조건(R2)을 선정하였다(Table 5). RS는 자유 수 면이 고정되어(Freezing) 유동이 발생하지 않는 조건이다. 접안 조건 R1에서 각 화물창의 수위는 FSRU $30 \%$, LNGC $95 \%$, 이송 조건 R2에서는 FSRU $67.5 \%$, LNGC $20 \%$ 이다. 화물창 내부 유 체로 물을 사용하였다. 화물창 내의 LNG는 저온의 액체로 모 형실험에서 물성치를 상사할 수 있는 유체가 거의 없기 때문에, 대부분의 슬로싱 모형실험에서 물을 내부 유체로 사용한다. 각 조건에서 FSRU의 설계 흘수 및 주요목은 동일하다. 그러나 LNGC는 RS, R2(20\%) 조건에서 경하 흘수이고, R1(95\%) 조건 에서는 만재 흘수가 $15.2 \mathrm{~m}$ 이다. LNGC의 R1 조건은 만재 흘수 에 해당하고 모형선과 $95 \%$ 로 채워진 화물창의 무게만으로 흘 수가 $15.2 \mathrm{~m}$ 가 된다. 따라서 R1 조건의 $\mathrm{LNGC}$ 는 $\mathrm{RS}, \mathrm{R} 2(20 \%)$ LNGC와 다른 운동응답(횡동요, 상하동요, 좌우동요 등) 특성을 보일 것이다.

\section{O 슬로싱 고유 주기}

각 조건에서 길이 및 폭 방향의 내부유동 고유 주기는 식(1)을 이용하여 근사값을 구할 수 있다. 식(1)은 Fig. 2과 같이 화물창 바닥 옆에 챔버가 있을 때 주기를 구하는 식이다(Flatinsen and Timokha, 2009). 각 적하 조건에 해당하는 수위에서 FSRU와 LNGC의 폭과 길이 방향에 대한 첫 번째 고유 주기를 구하여 Table 6과 7에 정리하였다.

$$
\omega^{\prime}=\omega \sqrt{1-\frac{\frac{\delta_{1}}{\delta_{2}} \sinh ^{2}\left(\frac{\pi i}{\mathrm{~B}} \delta_{2}\right)-\frac{\delta_{2}}{\delta_{1}} \sin ^{2}\left(\frac{\pi i}{\mathrm{~B}} \delta_{1}\right)}{\pi i \sinh \left(\frac{2 \pi i}{\mathrm{~B}} h\right)}}
$$

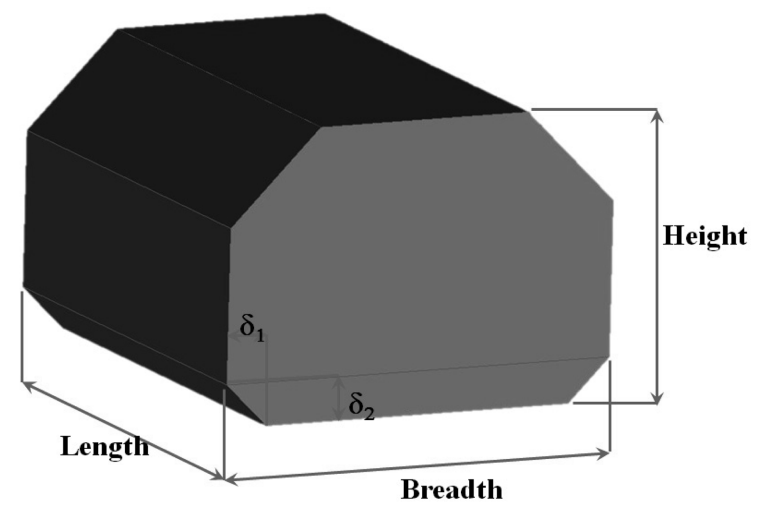

Fig. 2 Nomenclature of prismatic tank

Table 6 Natural period of transverse sloshing

\begin{tabular}{cccc}
\hline \hline & $\begin{array}{c}\text { Filling ratio } \\
{[\%]}\end{array}$ & \multicolumn{2}{c}{ 1st mode } \\
\cline { 3 - 4 } & 30 & Period [sec] & Frequency [rad/s] \\
\hline \multirow{2}{*}{ FSRU } & 67.5 & 7.67 & 0.65 \\
& 95 & 6.38 & 0.82 \\
\multirow{3}{*}{ LNGC } & 20 & 8.93 & 0.98 \\
& & & 0.70 \\
\hline
\end{tabular}

Table 7 Natural period of longitudinal sloshing

\begin{tabular}{cccc}
\hline \hline & Filling ratio & \multicolumn{2}{c}{ 1st mode } \\
\cline { 3 - 4 }$[\%]$ & Period [sec] & Frequency [rad/s] \\
\hline \multirow{2}{*}{ FSRU } & 30 & 8.61 & 0.73 \\
& 67.5 & 7.10 & 0.89 \\
\multirow{2}{*}{ LNGC } & 95 & 7.77 & 0.81 \\
& 20 & 12.43 & 0.51 \\
\hline
\end{tabular}

Table 8 Natural period of gap flow for gap distance $4.5 \mathrm{~m}$

\begin{tabular}{ccc}
\hline \hline \multirow{2}{*}{ Mode } & \multicolumn{2}{c}{ 1st mode } \\
\cline { 2 - 3 } & Period [sec] & Frequency $[\mathrm{rad} / \mathrm{s}]$ \\
\hline Piston & 7.85 & 0.80 \\
Transverse & 2.28 & 2.76 \\
Longitudinal & 7.31 & 0.86 \\
\hline
\end{tabular}

\section{$\mathrm{O}$ 틈새유동 고유 주기}

FSRU와 LNGC의 사이에서 발생하는 틈새유동은 피스톤, 폭 과 길이 방향의 슬로싱 모드로 이루어진다. 틈새에서 발생하는 유동의 주기는 Molin(2001)의 방법으로 구할 수 있다.틈새유동 의 주기는 Table 8 과 같다.

\section{3. 모형 실험 결과}

병렬 배치된 FSRU와 LNGC가 선수방향으로 입사하는 백색 소음 파를 맞아 나타내는 운동응답을 계측하였다. 화물창의 내 부유동 조건은 앞에서 기술한 바와 같이 슬로싱이 없는 조건(RS), FSRU 30\%-LNGC 95\%(R1), FSRU 67.5\%-LNGC 20\%(R2) 수위 조건이다. Fig. 3, 4, 5, 6 에서 실선은 FSRU, 점선은 $\mathrm{LNGC}$ 의 결 과를 나타낸다.

Fig. 3 은 각 조건에서의 전후동요 응답이다. RS 조건에서는 일 반적인 전후동요를 나타내지만, R1과 R2에서는 슬로싱에 의해 전후동요 국부 최대치가 발생한다. R1에서는 주파수 $0.75 \mathrm{rad} / \mathrm{s}$ 에서 $0.2 \mathrm{~m} / \mathrm{m}$ 의 FSRU 전후동요가 발생하고, $\mathrm{R} 2$ 에서는 주파수 $0.95 \mathrm{rad} / \mathrm{s}$ 에서 FSRU, $0.51 \mathrm{rad} / \mathrm{s}$ 에서 약 $0.5 \mathrm{~m} / \mathrm{m}$ 의 LNGC 전 후동요 국부 최대치가 발생한다. R2 조건에서 LNGC의 전후동요 국부 최대치는 슬로싱 고유주파수에서 발생하고, $\mathrm{FSRU}$ 의 전후동 요 국부 최대치는 슬로싱 고유주파수보다 큰 주파수에서 발생한다.

Fig. 4 는 좌우동요 응답 결과이다. RS 조건에서는 틈새유동에 의해 $0.9 \mathrm{rad} / \mathrm{s}$ 에서 $0.2 \mathrm{~m} / \mathrm{m}$ (LNGC), $0.1 \mathrm{~m} / \mathrm{m}$ (FSRU)의 국부 최 대치가 발생한다. 틈새유동의 피스톤 모드 주파수는 $0.80 \mathrm{rad} / \mathrm{s}$, 슬로싱 모드 주파수는 $0.86 \mathrm{rad} / \mathrm{s}$ 이다. 수치해석에 따르면 피스톤 모드가 좌우동요를 발생시키지만, 실험에서 나타난 좌우동요는 피스톤 모드와 슬로싱 모드의 영향이다. 이는 선수동요 국부 최 대치가 $0.9 \mathrm{rad} / \mathrm{s}$ 에서 발생하는 것으로도 확인할 수 있다. 주파 수 $0.46 \mathrm{rad} / \mathrm{s}$ 에서 나타나는 LNGC 좌우동요는 횡동요와 연성되 어 나타나는 응답이다. R1 조건에서 주파수 $0.69 \mathrm{rad} / \mathrm{s}$ 에서 나타나 는 FSRU의 좌우동요 국부 최대치는 횡방향 슬로싱(고유 주파 수 $0.65 \mathrm{rad} / \mathrm{s}$ )에 의한 것이다. 한편 RS 조건, 주파수 $0.9 \mathrm{rad} / \mathrm{s}$ 에서 나타났던 틈새유동에 의한 좌우동요는 R1 조건에서는 

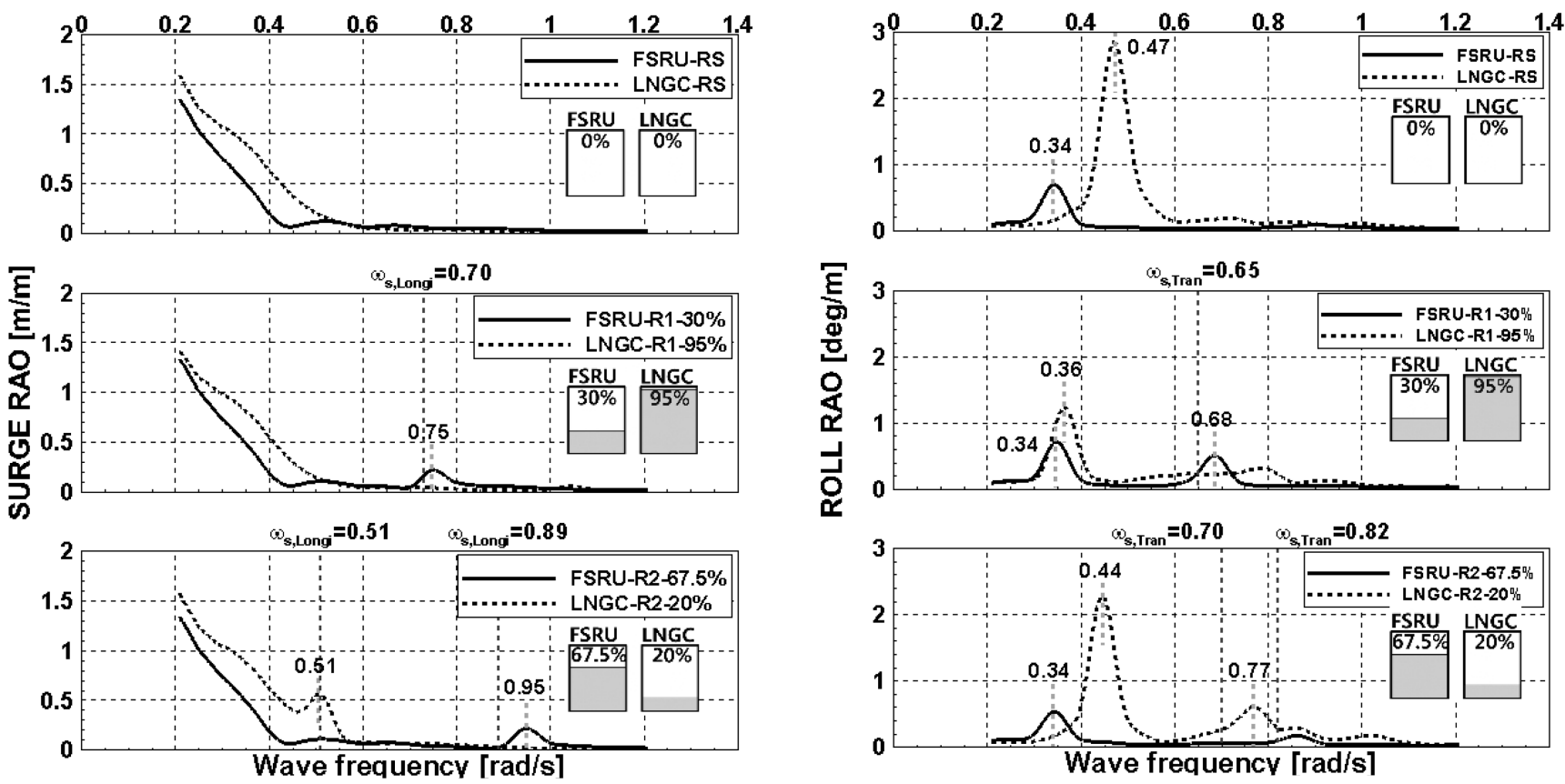

Fig. 3 Surge RAO of FSRU-LNGC for white noise in head sea

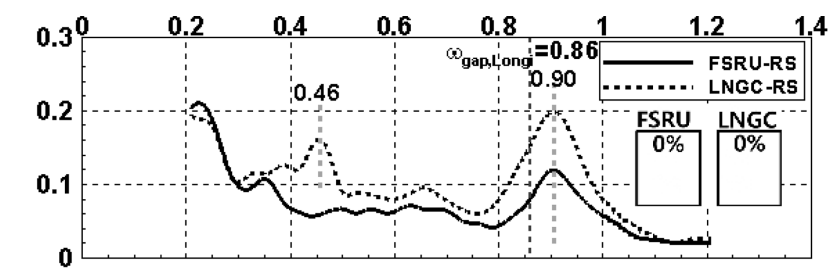

Fig. 5 Roll RAO of FSRU-LNGC for white noise in head sea
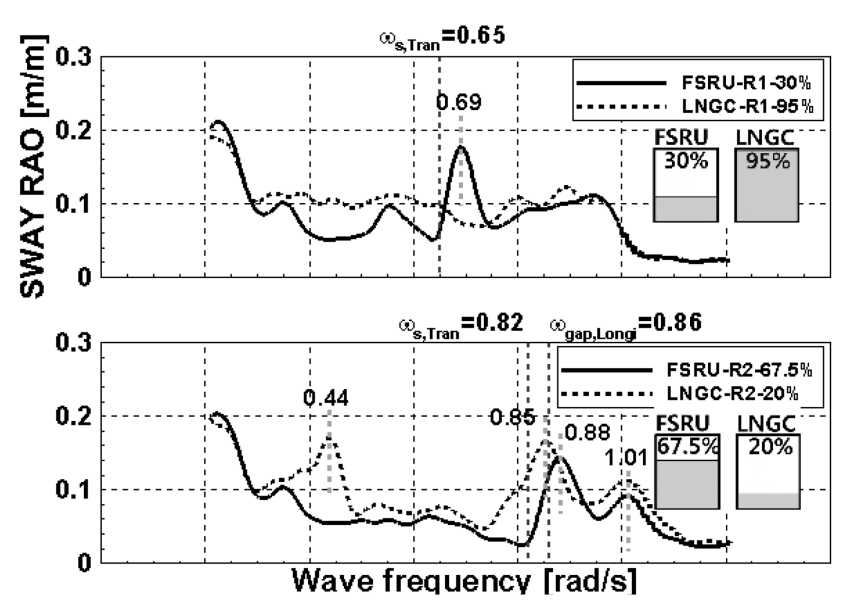

Fig. 4 Sway RAO of FSRU-LNGC for white noise in head sea

슬로싱에 의해 억제되어 발생하지 않는다. 슬로싱은 고유 주파 수에서 좌우동요를 발생시키고, 틈새유동에 의한 좌우동요를 억제하는 감쇠로 작용함을 알 수 있다. R2 조건에서는 주파수 $0.88 \mathrm{rad} / \mathrm{s}(\mathrm{FSRU}), 0.86 \mathrm{rad} / \mathrm{s}(\mathrm{LNGC})$ 에서 국부 최대치가 발생한 다. 이 때 FSRU의 횡방향 슬로싱의 고유 주파수는 $0.82 \mathrm{rad} / \mathrm{s}$ 이 고 LNGC 횡방향 슬로싱의 고유 주파수는 $0.70 \mathrm{rad} / \mathrm{s}$ 이다. 주파 수 $0.44 \mathrm{rad} / \mathrm{s}$ 에서 나타나는 LNGC 좌우동요는 횡동요 공진에 의한 것이다.
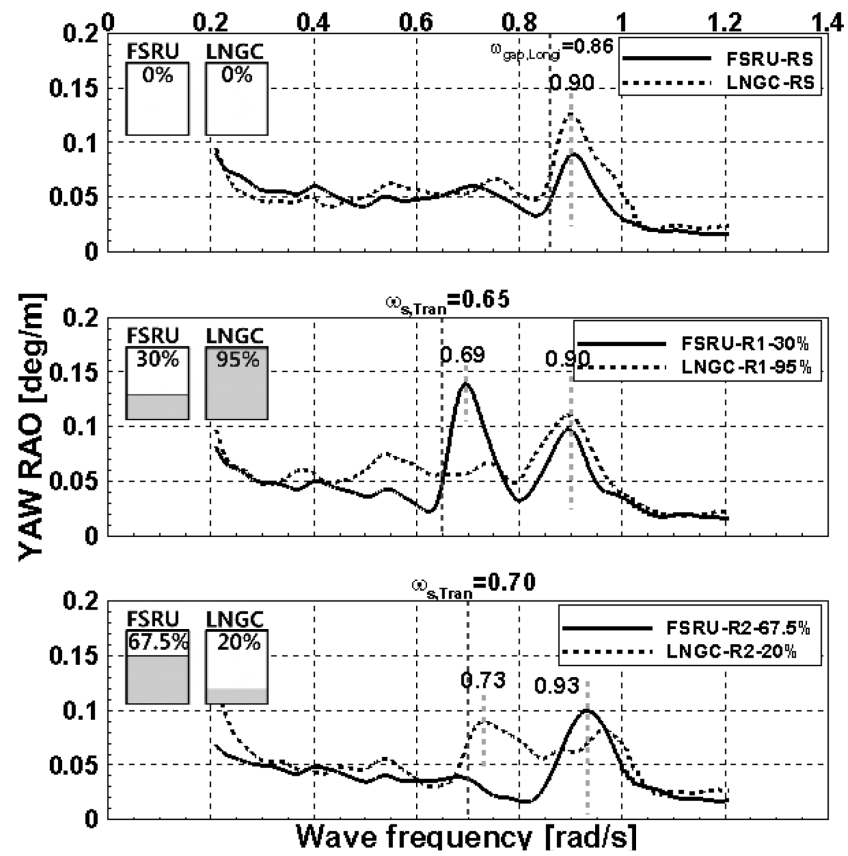

Fig. 6 Yaw RAO of FSRU-LNGC for white noise in head sea

Fig. 5는 횡동요 응답 결과이다. RS 조건의 결과는 선수파 조 건이지만, 병렬배치에 의한 틈새유동으로 인해 횡동요 국부 최 대치가 발생함을 알 수 있다. 주파수 $0.47 \mathrm{rad} / \mathrm{s}$ 에서 LNGC 횡 동요가 $2.9 \mathrm{deg} / \mathrm{m}$ 까지 발생한다. R1 조건에서는 $\mathrm{LNGC}$ 의 횡동 요는 적하 변화에 의해 주파수 $0.36 \mathrm{rad} / \mathrm{s}$ 에서 약 $1.2 \mathrm{deg} / \mathrm{m}$ 크 기로 나타나고, 주파수 $0.68 \mathrm{rad} / \mathrm{s}$ 에서 FSRU 횡동요가 작게 발 생한다. R2 조건에서 슬로싱에 의해 LNGC 공진 횡동요는 소폭 감소하고 $0.77 \mathrm{rad} / \mathrm{s}$ 에서 $0.5 \mathrm{deg} / \mathrm{m}$ 의 횡동요가 발생한다. 
Fig. 6은 선수동요 응답결과로 좌우동요와 유사한 경향을 나 타낸다. RS 조건에서 틈새유동에 의해 $0.9 \mathrm{rad} / \mathrm{s}$ 에서 선수동요 국부 최대치가 발생하고, R1 조건에서는 슬로싱에 의해 $0.69 \mathrm{rad} / \mathrm{s}$ 에서 FSRU 선수동요가, R2에서는 $0.93 \mathrm{rad} / \mathrm{s}$ 에서 FSRU 선수동 요 국부 최대치가 발생한다. 슬로싱은 틈새유동에 의한 좌우동요 를 억제하였지만, 틈새유동에 의한 선수동요는 슬로싱에 의한 영 향을 받지 않는 것을 알 수 있다.

실험 결과에서 주목할 점은 슬로싱에 의해 발생하는 응답이 계 산된 슬로싱 고유 주파수보다 큰 주파수에서 나타나는 현상이다. 각 적하 조건에서 주파수 차이는 Table 9와 10과 같고, 틈새유 동에 의해 발생하는 응답의 주파수 차이는 Table 11과 같다. 이러 한 주파수의 차이를 설명하기 위해서는 슬로싱에 의해 발생하는 모멘트를 살펴보아야 한다. 슬로싱에 의하여 발생하는 모멘트 의 크기와 위상은 van Daalen et al.(2001)이 모형시험과 COMFLO (CFD)를 이용하여 분석한 바 있다. van Daalen의 결과에 의하 면 Fig. 7과 같이 슬로싱 모멘트의 위상은 저주파수에서 0deg이 다가, 슬로싱 고유 주파수에 가까워지면서 증가한다. 이 때 슬 로싱 고유 주파수에서 위상은 약 $-60 \mathrm{deg}$ 이고, 고유 주파수의 1.2 1.3 배 정도 되는 주파수에서 위상이 $-90 \mathrm{deg}$ 가 된다. 주파수가 증가하면 위상은 $-180 \mathrm{deg}$ 가 된다. 슬로싱 모멘트가 운동에 최대 로 영향을 주는 위상은 -90deg이고, 이 때 주파수는 슬로싱 고유 주파수보다 1.2 1.3배 정도 크다. 또한 van Daalen은 위상이 슬 로싱 탱크의 회전 중심과 슬로싱 탱크의 폭에도 영향을 받음을 확인하였고, 슬로싱 수위가 증가할수록 주파수 차이는 감소함을 실험과 계산으로 보여주었다. 이는 슬로싱 수위가 커질수록 유 동이 작아지기 때문이며, 수위가 탱크 윗면까지 완전히 차거나, 자유 수면이 고정되어 움직이지 않는 조건이 되면 RAO 국부 최 대치는 슬로싱 고유 주파수에서 나타난다.

O van Daalen et al.(2001): Filled: Experiment, Blank: COMFLO $\triangle: 8 \%(h / B=0.04), \omega / \omega_{0} \simeq 1.39$ at $\epsilon_{M}=-90 \mathrm{de} g$

Table 9 Difference between actual peak in RAO and natural sloshing frequency of 2BODY-R1 in head sea

\begin{tabular}{cccccc}
\hline \hline & \multirow{2}{*}{$\begin{array}{c}\text { Filling } \\
\text { ratio [\%] }\end{array}$} & Mode & \multicolumn{2}{c}{ Frequency } & Measured/ \\
\cline { 4 - 6 } & & Calculated & Measured & Calculated \\
\hline \multirow{2}{*}{ FSRU } & \multirow{2}{*}{30} & Longi & 0.73 & 0.75 & 1.03 \\
& & Trans & 0.65 & 0.68 & 1.05 \\
\multirow{2}{*}{ LNGC } & \multirow{2}{*}{95} & Longi & 0.81 & - & - \\
& & Trans & 0.98 & - & - \\
\hline
\end{tabular}

Table 10 Difference between actual peak in RAO and natural sloshing frequency of 2BODY-R2 in head sea

\begin{tabular}{cccccc}
\hline \hline & \multirow{2}{*}{$\begin{array}{c}\text { Filling } \\
\text { ratio [\%] }\end{array}$} & Mode & \multicolumn{2}{c}{ Frequency } & Measured/ \\
\cline { 4 - 5 } & & Calculated & Measured & Calculated \\
\hline \multirow{2}{*}{ FSRU } & \multirow{2}{*}{67.5} & Longi & 0.89 & 0.95 & 1.07 \\
& & Trans & 0.82 & 0.88 & 1.07 \\
\multirow{2}{*}{ LNGC } & \multirow{2}{*}{20} & Longi & 0.51 & 0.51 & 1.00 \\
& & Trans & 0.70 & $0.77 / 0.85$ & 1.10 \\
\hline
\end{tabular}

Table 11 Difference between actual peak in RAO and natural frequency of GAP flow

\begin{tabular}{|c|c|c|c|}
\hline \multirow{2}{*}{ Mode } & \multicolumn{2}{|c|}{ Frequency } & \multirow{2}{*}{$\begin{array}{l}\text { Measured/ } \\
\text { Calculated }\end{array}$} \\
\hline & Calculated & Measured & \\
\hline Longitudinal & 0.85 & 0.90 & 1.06 \\
\hline
\end{tabular}

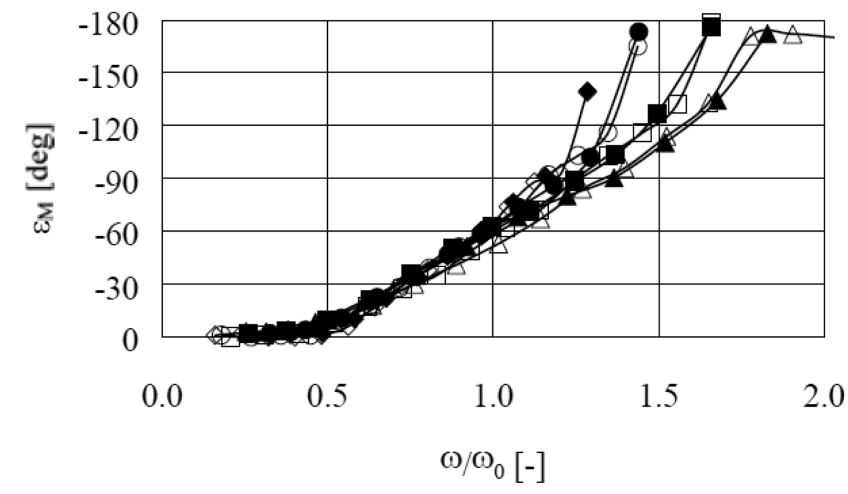

Fig. 7 Phase angle for filling ratios (van Daalen et al., 2001)

$$
\begin{aligned}
& \square: 12 \%(h / B=0.06), \omega / \omega_{0} \simeq 1.27 \text { at } \epsilon_{M}=-90 \mathrm{deg} \\
& \bigcirc: 16 \%(h / B=0.08), \omega / \omega_{0} \simeq 1.20 \text { at } \epsilon_{M}=-90 \mathrm{deg} \\
& \diamond: 20 \%(h / B=0.10), \omega / \omega_{0} \simeq 1.20 \text { at } \epsilon_{M}=-90 \mathrm{de} g
\end{aligned}
$$

병렬 배치에서 전후동요 평균 표류력 결과는 Fig. 8(FSRU), 9 (LNGC)와 같다. FSRU는 R1 조건에서 슬로싱에 의해 $0.75 \mathrm{rad} / \mathrm{s}$ 에서 전후동요가 발생하며, 표류력은 $0.75 \mathrm{rad} / \mathrm{s}$ 을 기준으로 양 쪽에서 약 $45 \mathrm{kN} / \mathrm{m}^{2}$ 감소한다. $\mathrm{LNGC}$ 는 R1 조건에서 전후동요 와 표류력의 변화가 없다. R2에서는 슬로싱에 의해 FSRU와 LNGC 전후동요가 발생하지만, 표류력의 변화는 없는 것을 확인하였다.

좌우동요 평균 표류력 결과는 Fig. 10(FSRU), 11(LNGC)와 같 다. 좌우동요 표류력은 주파수 $0.8 \mathrm{rad} / \mathrm{s}$ 부터 RS 조건에 비해 R1, R2의 표류력이 작게 나타난다. 이는 Fig. 4 에서 보인 바와 같이 $\mathrm{R} 1$ 과 R2의 좌우동요 응답이 RS에 비해 작기 때문에, 평균 표류 력의 1 차 선형 운동 성분이 감소하기 때문임을 추정할 수 있다.

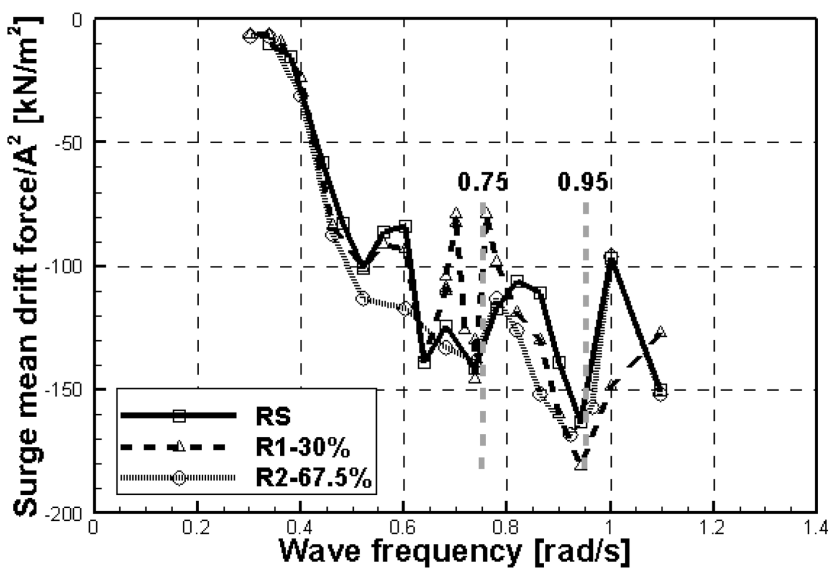

Fig. 8 Surge drift force of FSRU of 2BODY in head sea 


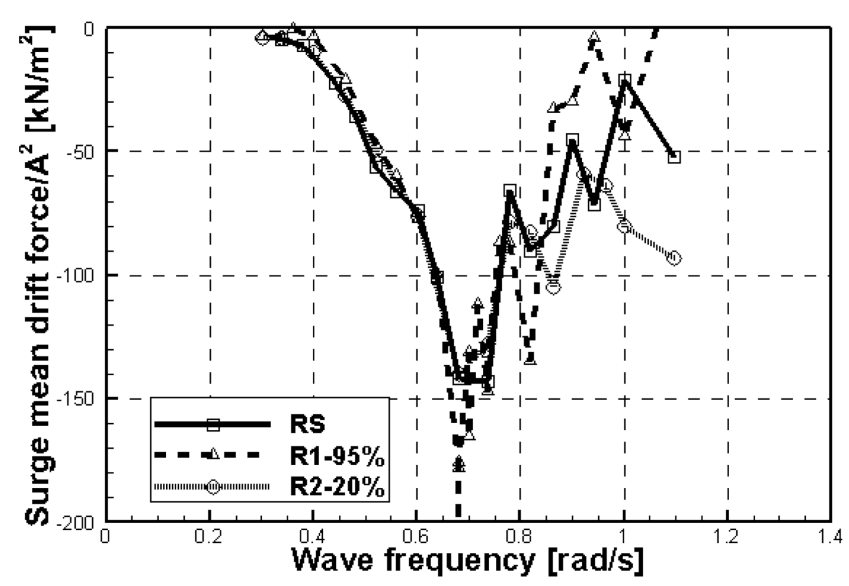

Fig. 9 Surge drift force of LNGC of 2BODY in head sea

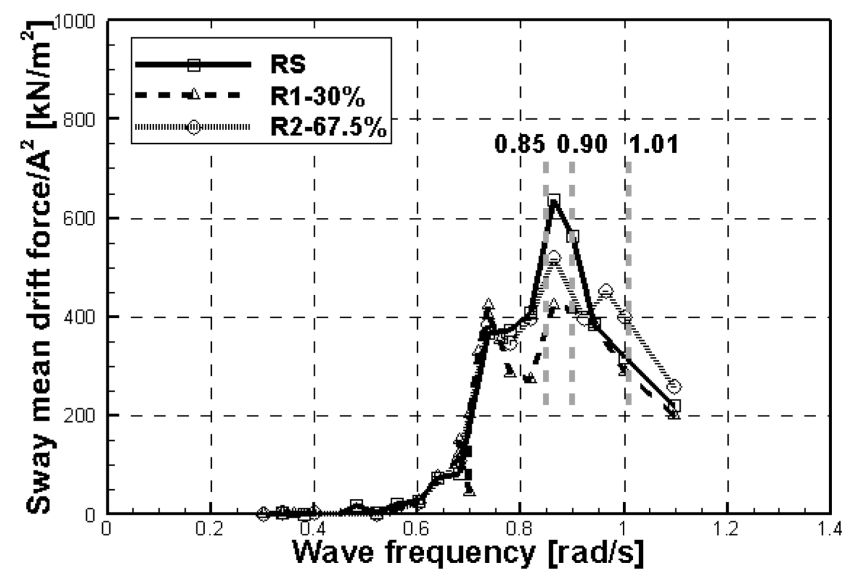

Fig. 10 Sway drift force of FSRU of 2BODY in head sea

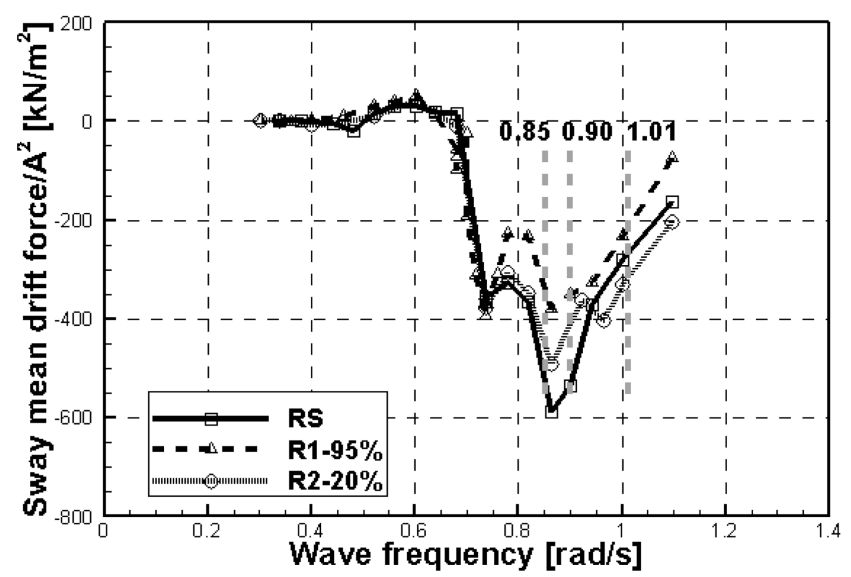

Fig. 11 Sway drift force of LNGC of 2BODY in head sea

\section{5. 결 론}

본 연구에서는 슬로싱을 고려한 병렬배치된 FSRU와 LNGC 의 모형실험을 수행하였다. FSRU와 LNGC을 선형 스프링으로 계류하고 LNG 화물창을 설치하여 슬로싱과 틈새유동이 운동과 표류력에 주는 영향을 살펴보았다. 슬로싱 공진에 의해 전후동
요, 좌우동요, 횡동요가 발생하고, 이 때 슬로싱 공진 주파수보다 조금 높은 주파수에서 슬로싱에 의한 운동 응답 국부 최대치가 발생하는 것을 확인하였다. 이는 슬로싱 모멘트가 운동에 최대로 영향을 주는 위상 -90deg가 슬로싱 고유 주파수의 약 1.2 1.4배 에서 나타나기 때문이다. 선수파 중에서 길이 방향의 틈새유동에 의해 좌우동요, 선수동요가 발생하고, 슬로싱에 의해 전후동요, 좌우동요, 횡동요, 선수동요가 영향을 받는 것을 확인하였다. 슬 로싱은 내부 수위에 따라 영향의 정도가 다르며, 수위가 낮을수 록 슬로싱의 영향이 크고, 틈새유동에 의한 좌우동요를 억제하는 작용을 한다. 표류력 또한 수위가 낮은(30\%) 조건에서 슬로싱의 영향을 강하게 받는다. 선수파 중에서 슬로싱은 전후동요, 좌우동 요, 횡동요, 선수동요에 영향을 주고, 횡동요에 대한 영향은 미미하 다. 틈새유동은 좌우동요와 선수동요에 영향을 주는 것을 알 수 있다.

부유체가 터렛 계류되어 자유롭게 선수각 회전이 가능할 때, 이러한 슬로싱과 틈새유동은 운동과 계류 하중에 영향을 줄 수 있고, 선수각 회전에 따라 특성이 달라질 수 있다. 따라서 계류 방법에 따라 슬로싱과 틈새유동의 영향을 고려해야 부유체 운 동, 계류 하중, 작업 가능성 등을 정확하게 평가할 수 있을 것이다.

\section{후기}

본 연구는 한국해양과학기술원의 주요연구사업 "해양구조물 의 이송 - 설치를 위한 작업성능 평가기술 개발 $(2 / 3)$ "과 지식경 제부의 전략기술개발사업 “해상 LNG터미널 (FSRU) 엔지니어 링 기술개발 (2단계 1 차년도)"의 결과 중 일부임을 밝힙니다.

\section{참 고 문 헌}

Cho, S.K., 2012. A Study on the Motion Behaviour of Sideby-Side Moored Two Floaters Including Sloshing Effects. $\mathrm{PhD}$ Thesis, Seoul National University, KOREA.

Cho, S.K., Sung, H.G., Hong, S.Y., Hong, S.W., 2011. Experimental Study on the Effect of Sloshing on Side-by-Side moored FSRU and LNGC. Proceedings of 21th International Offshore and Polar Engineering Conference (ISOPE), Maui USA.

Cho, S.K., Sung, H.G., Hong, S.Y., Hong, S.W., 2012. Experimental Study on the Side-by-Side Offloading Operation of FSRU and LNGC. Proceedings of 22th International Offshore and Polar Engineering Conference (ISOPE), Rhodos Greece.

Clauss, G.F., Testa, D., Sprenger, F., 2010. Coupling Effect Between Tank Sloshing and Motions of a LNG Carriers. Proceedings of 29th International Conference Ocean, Offshore and Arctic Engineering (OMAE), Shanghai China.

Faltinsen, O.M., Timokha, A.N., 2009. Sloshing. Cambridge University.

Gaillarde, G., Ledoux, A., Lynch, M., 2004. Coupling between Liquified Gas and Vessel's Motion for Partially 
Filled Tanks: Effect on Seakeeping, Design \& Operation of Gas Carriers. RINA.

Hansen, H.F., Cartensen, S., Christensen, E.D. and Kirkegaard, J., 2009. Multi Vessel Interaction in Shallow Water. Proceedings of 28th International Conference Ocean, Offshore and Arctic Engineering (OMAE), Hawaii USA.

Hong, S.Y., Kim, J.H., Cho, S.K., Choi, Y.R., Kim, Y.S., 2005. Numerical and Experimental Study on Hydrodynamic Interaction of Side-by-Side Moored Multiple Vessels. Ocean Engineering, 32, 783-801.

Hong, Y.P., Wada, Y., Choi, Y., Kim, S., 2009. An Experimental and Numerical Study on the Motion Characteristics of Side-by-Side Moored LNG-FPSO and LNG Carrier. Proceedings of 19th International Offshore and Polar Engineering Conference (ISOPE), Osaka Japan.

Jeong, H.S., Kim, M., Lee, J., Kim, B., Ha, M.G., 2010. Offloading Operability Analysis of Side-by-Side Moored LNG FPSO. Proceedings of 9th ISOPE Pacific/Asia Offshore Mechanics Symposium, Busan Korea.

Kim, Y.H., Nam, B.W., Kim D.W., Kim, Y.S., 2007. Study on Coupling Effects of Ship Motion and Sloshing. Ocean Engineering, 34, 2176-2187.

Lee, S.J., Kim, M.H., 2008. The Effects of Tank Sloshing on LNG Vessel and Floating Terminal Responses. IWWWFB.

Lee, S.J., Kim, M.H., Lee, D.H., Kim, J.W., Kim, Y.H., 2007. The Effects of LNG Tank Sloshing on the Global Motions of LNG Carriers. Ocean Engineering, 34, 10-20.

Molin, B., 2001, On the Piston and Sloshing Modes in Moonpools. Journal of Fluid Mechanics, 430, 27-50.

Pinkster, J.A., 1980. Low Frequency Second Order Wave Exciting Forces on Floating Structures. PhD Thesis, MARIN, Netherland.

Rognebakke, O.F., Faltinsen, O.M., 2003. Coupling of Sloshing and Ship Motions. Journal of Ship Research, 47(3), 208-221.

van Daalen E.F.G., Kleefsman, K.M.T., Gerrits, J., Luth, H.R., Veldman, A.E.P., 2001. Anti-Rolling Tank Simulations with a Volume of Fluis(VOF) Based Navier-Stokes Solver. Proceedings of 23rd Symposium on Naval Hydrodynamics. 